\title{
Innovative consolidating products for stone materials: field exposure tests as a valid approach for assessing durability
}

\author{
Irene Natali $i^{*}$, Patrizia Tomasin ${ }^{3}$, Francesca Becherini ${ }^{2}$, Adriana Bernardi ${ }^{2}$, Chiara Ciantelli ${ }^{1}$, Monica Favaro ${ }^{3}$, \\ Orlando Favoni ${ }^{4}$, Vicente J Forrat Pérez ${ }^{5}$, Iulian D Olteanu ${ }^{6}$, Maria Dolores Romero Sanchez ${ }^{5}$, Arianna Vivarelli ${ }^{2}$ \\ and Alessandra Bonazza ${ }^{1}$
}

\begin{abstract}
The impact of climate on cultural heritage surfaces leads to several damage processes and the protection and the preservation of works of art is a challenge for conservation scientists and restorers. Traditional and innovative products are used in consolidating treatments in order to reduce the effects of the interaction environment-materials. The EC NANOMATCH Project aims at the development of innovative consolidating agents for carbonate matrices, wood and glass whose features should result in high compatibility, efficiency and long-lasting effect. In this project, metal alkoxides, molecular precursors for the deposition of metal carbonate are synthesized, characterized, tested and proposed as an alternative to traditional consolidating agents as well as to calcium hydroxide nanoparticles. This paper gives an overall description of the methodological approach adopted for the in field evaluation of durability taking into account the environmental impact. Preliminary results of the analyses carried out on carbonate stones aimed at investigating the features of the consolidating treatment are here presented and discussed.
\end{abstract}

Keywords: Consolidating treatments, Metal alkoxides, Durability, Climate impact, Carbonate stones, Cultural heritage conservation

\section{Introduction}

Climate is predicted to change in the near and far future. The EC NOAH'S ARK Project [1-3] has contributed to the production of scenarios and maps representing the European situation concerning climatic events and related damage processes affecting outdoor built cultural heritage. The foreseen impact of climate change on carbonate stone, marble and limestone, for the 21st century indicates that they will undergo an increase of surface recession, resulting mainly from the yearly precipitation amount and the rise in carbon dioxide concentration; in addition, thermal stress will be experienced by marble, and increased salt crystallization by porous stone [4-7]. Although knowledge on deterioration processes of building materials have been greatly improved, no really

\footnotetext{
* Correspondence: i.natali@isac.cnr.it

'Istituto di Scienze dell'Atmosfera e del Clima, Consiglio Nazionale delle Ricerche (ISAC-CNR), Bologna, Italy

Full list of author information is available at the end of the article
}

effective solutions to preserve and protect these materials have been found yet.

Both organic and inorganic consolidating products have been traditionally used in order to recover the mechanical properties of damaged materials of built heritage. A wide range of synthetic polymers has been extensively used in stone conservation treatments, but their long lasting efficacy and performance in preventing further deterioration has been recently drastically reconsidered as they frequently undergo chemical modifications induced both by environmental conditions and irreversibility of the treatment [8-10]. Traditional inorganic treatments, though usually more compatible with the carbonate matrices, suffer from low solubility and therefore a resulting low amount of applied product as well as from a scarcely cohesive effect. Penetration depth, physico-chemical compatibility, stability, absence of by-products and partial filling of porosity are those characteristics to be evaluated in choosing the best consolidating material for a valid conservation treatment. 
In the last decade nanomaterials have been specifically developed for restoration procedures. In particular calcium, magnesium, barium hydroxide nanoparticles have been largely studied and their potentiality as surface consolidating agents has been demonstrated [11-13]. Although these innovative materials have been extensively characterized, little is known about their behaviour in outdoor environment and their durability.

The EC NANOMATCH Project is aimed at developing innovative consolidating products for carbonate matrices, wood and glass. In particular, metal alkoxides have been identified and then synthesized as molecular precursors for the deposition of metal carbonate as consolidating agent for carbonate stones, the same product as alkaline reservoir to prevent acidity of wooden materials and metal oxide as a glass consolidant. Alkaline earth and semimetal alkoxides are suitable molecular precursors because the corresponding solutions or nanoparticulate inorganic sols, upon evaporation of the solvent based carrier, undergo hydrolysis and condensation or carbonation inside the porous structure of the substrate. Particularly, calcium alkoxides, acting as precursors of corresponding carbonate $[14,15]$, can be considered for stone strengthening as an indispensable and essential preliminary action for its conservation, as demonstrated within the bilateral Italian-French GALILEO Project [16]. The same material has been used for wood as these materials, besides strengthening effects, also ensure an alkaline supply to mitigate acidic deterioration processes of cellulose structures.

The expected features making them competitive respect to conventional conservation products are their (i) compatibility with the main materials used in built heritage like stone and wood -even painted- and glass, ensuring enhanced durability, re-treatability, sustainability and efficiency, (ii) easy and safe handling during applications, (iii) satisfactory selling prices.

In this paper we will briefly describe the methodological approach adopted for the evaluation in field of the performances of newly developed products compared to commercial ones applied on carbonate stones. Furthermore, the study here presented is part of the experimental work carried out within the project to achieve an exhaustive performance evaluation of the developed material by investigating its efficacy, compatibility and durability. As the latter aspect is intimately linked to climate impact, environmental parameters having a crucial role in damage processes have been prioritized for a correct evaluation of the durability of the NANOMATCH product during the test in field. Climate parameters have been considered more important than pollution parameters in addressing the objectives of the NANOMATCH project. The main parameters linked to climate change and trigging future damage on materials constituting immovable and movable heritage have been identified from the results of previous EU projects [17-21] and taken into account for the definition of methodologies to assess long-term behaviour of treatments. Rain, relative humidity, air temperature, wind, solar radiation contribute to trigger decohesion processes affecting carbonate stones and therefore believed to have priority for the evaluation of the compatibility, efficiency and performance of nano-structured materials in field. In addition, surface temperature has been also taken into account as an important parameter linked to the material constituent the work of art. The aim of this paper is to highlight how field exposure tests can constitute a valid tool to investigate compatibility and durability of innovative nanostructured consolidating agents, specifically developed to be applied on outdoor built heritage surfaces. The methodological approach adopted to achieve the project objectives is described and part of the results obtained by analysing samples before/after treatment and after exposure by means of different analytical techniques are presented and discussed.

\section{Materials and methods}

\section{Synthesis of calcium alkoxides}

Different synthetic routes have been tested and more than 20 different alkoxides have been obtained in order to identify the right products and the suitable methodology for its production at industrial scale. In first instance, calcium and magnesium alkoxides were believed adequate to be used in the field of conservation of cultural heritage.

Synthesis of calcium alkoxides, involving ammonia gas-assisted reactions with the corresponding alcohol, have been carried out in nitrogen-filled gloves-boxes with the exclusion of moisture and oxygen according to procedures already described in the literature [22]. The reaction mixture can arise as a white suspension or as a clear solution depending on the alkoxide: in the case of a white suspension, the white precipitate is recovered by centrifugation while in the case of a clear solution, the product is recovered by solvent evaporation.

Then, two alkoxides have been selected on the basis of their properties (solubility in common organic solvents, volatility of the corresponding alcohol, low toxicity): $\mathrm{Ca}\left(\mathrm{OCH}_{2} \mathrm{CH}_{3}\right)_{2} \quad(\mathrm{NANOMATCH} 2)$ and a $\mathrm{Ca}(\mathrm{OTHF})_{2}$, where THF = tetrahydrofurfuryl moiety (NANOMATCH1). These have been up-scaled to produce about $3 \mathrm{Kg}$ of each compound.

Although several synthetic methodologies can be used [23] to synthesize magnesium alkoxides, preliminary carbonation tests performed with available commercial products demonstrated that they are unsuitable for conservation of built heritage $[24,25]$. 


\section{Coatings investigation}

Figure 1 show the possible pathways for the formation of calcium carbonate from calcium alkoxides. To assess the kinetic and the final products of the carbonation process, the calcium alkoxides produced by different synthetic pathways have been dissolved in alcohol and deposited on suitable substrates. The corresponding coatings have been analysed by different techniques (FT-IR, XRD; FEG ESEM) and details can be found in papers by Favaro et al. (2013) [24,25].

The effects of solvents and different relative humidity conditions (50 and 90\%) on carbonation rate and phase formation as well as the effects of outdoor environment and liquid water have been investigated. The results evidenced the complexity of carbonation process, where the most kinetically favoured vaterite is always formed but it can evolve to the thermodynamically stable calcite by addition of water and with high relative humidity. The choice of the solvent is extremely important to control carbonation rate: higher vapour pressure (fast evaporation rate) leads to faster carbonation. Slow carbonation is also related to the formation of the thermodynamically favoured phase calcite.

\section{Lithotypes selection and application trials}

The selection of stones has been restricted to carbonate ones since the Ca-alkoxide products developed in the NANOMATCH project are mainly meant for the consolidation of calcite-based matrices by deposition of calcium carbonate. Stone materials have been selected on the basis of their Water Absorption Coefficient (WAC) and total porosity. In particular, lithotypes characterized by having very different values of these two properties have been chosen; then, the final choice took into account stones presenting extreme, completely different values of total porosity and WAC.

Therefore, Carrara marble, Savonnières limestone, Laspra dolostone and Albeşti limestone have been selected and used for testing in field (vide infra). Moreover, as the Ca-alkoxide products developed in the project aimed at treating substrates presenting granular disintegration (sugaring, powdering, sanding), it has been decided to carry out the tests on both sound stones and artificially deteriorated stones. Other lithotypes have been tested in laboratory as part of the experimental work planned within the project (Figure 2a), not presented in this paper.

Moreover, the Ca-alkoxide consolidants developed during the NANOMATCH project have been compared to a commercial consolidants currently on the market, $\mathrm{CaLoSiL}^{\bullet}$ manufactured by IBZ-Salzchemie (Freiberg, Germany).

A number of application trials (Figure 2b) have been carried out on all stones in order to optimize the application parameters of both compounds. The trials enabled to select the application solvent, the product concentration and the application conditions that gave the best results. Four different solvents ( 2 alcohols and 2 hydrocarbon based) or mixture of them at different concentration have been applied on the different lithotypes.

The best results have been obtained with solution of alkoxides with $20 \mathrm{~g} / \mathrm{L}$ of $\mathrm{Ca}$ in ethanol:ligroin 1:1 applied by brush for two times (different application methods/ condition gave worse results), on the basis of visual appearance, amount of consolidant introduced as well as scratch test.

\section{Tests in field}

Four European monuments have been selected as field exposure sites. For each of them one typical lithotype (Table 1) has been chosen to carry out the experimental work in order to assess the performance of the product when exposed to different natural conditions. In particular, Carrara marble, Savonnières limestone (oolitic limestone), Laspra dolostone and Albeşti limestone (nummulitic limestone) are lithotypes representative of Santa Croce Basilica in Florence, Cologne Cathedral, Oviedo Cathedral and Stavropoleos Monastery, respectively. Plaques with size of $10 \times 10 \times 5 \mathrm{~cm}^{3}$ for each lithotype has been prepared as model samples in order to test in field efficacy, compatibility towards stone and durability against climate impact of the alkaline earth metal alkoxides as consolidating agents. Although Carrara marble is typical of Florentine architecture, this lithotype has been exposed in all four sites together with one local lithotype, to evaluate the impact of climate on the same stone in different European geographical areas.

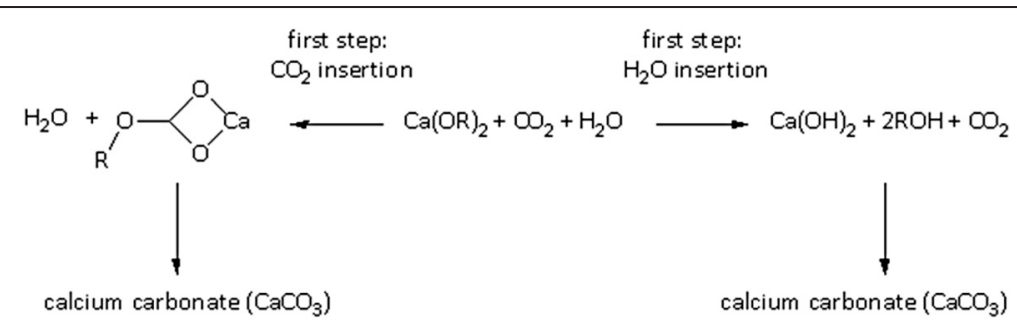

Figure 1 Possible pathways for the formation of $\mathrm{CaCO}_{3}$ from $\mathrm{Ca}(\mathrm{OR})_{2}$ : insertion of $\mathrm{CO}_{2}$ can either follow or precede the hydrolysis. 


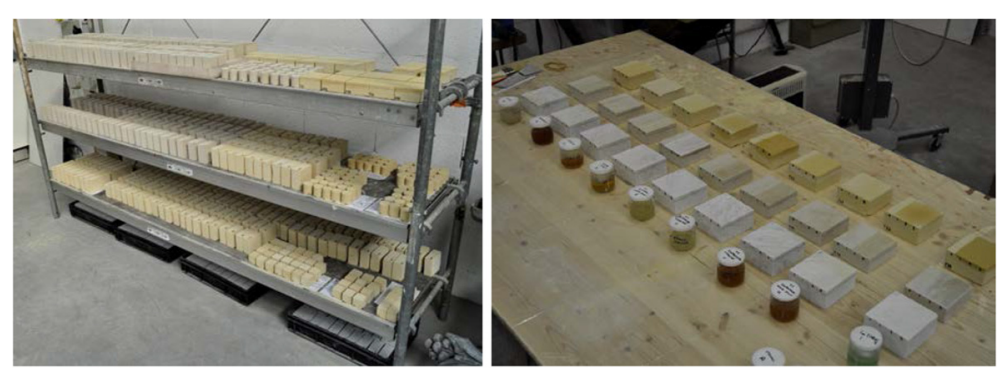

Figure 2 Samples of the stones selected for testing (left); application trials on different lithotypes (right).

For the exposure test, Carrara marble and Savonnières limestone have been previously artificially damaged respectively by thermal shock (heating treatment at $600^{\circ} \mathrm{C}$ for $1 \mathrm{~h}$ ) and by contamination with sodium sulfate (5\% w/w $\mathrm{Na}_{2} \mathrm{SO}_{4}$ solution). The thermal shock carried out on Carrara marble was aimed exclusively at obtaining samples characterized by a heavy intergranular decohesion (damage effect) without any purpose of simulating a realistic outdoor damage process. A set of samples of each of the two types of stone has been exposed undamaged, while four samples of each lithotype have been treated with the NANOMATCH1 product. Other identical sets have been treated with $\mathrm{CaLoSiL}^{\circ}$ in order to make a comparison. Table 2 summarizes the artificial deterioration and the consolidating treatments carried out on the four lithotypes.

Model samples have been placed in galvanized rack (Figure 3) specifically built for field testing, located outdoor in an unsheltered area, exposed to environmental impact so that at each site of exposure specimens of the local lithotype are present and Carrara marble as well. Samples were exposed for 11 months in each site, from April/May 2013 to March/April 2014. In Florence the rack has been installed outside on the roof above the Pazzi's and Castellani's Chapels in the south-west side of Santa Croce Basilica. In Cologne the rack was installed at $20 \mathrm{~m}$ height on a small outside balcony at the south side of the Cathedral. Concerning Oviedo, samples have been placed in the "Patio de Carton", on the south side of the Cathedral, while in Bucharest in the southeast side of the courtyard of the Monastery. Climatic and microclimatic data (rain, wind, solar radiation, relative humidity, air and surface temperature) were continuously collected outdoors nearby the rack, close to the samples exposed, they were analysed, and their temporal evolution for the whole duration of the exposure was studied. During the monitoring campaign Florence and Oviedo were characterized by the highest cumulative amounts of rainfalls, both around $820 \mathrm{~mm}$, followed by Cologne $(460 \mathrm{~mm})$ and Bucharest $(275 \mathrm{~mm})$. Florence and Oviedo were also characterized by the highest rain monthly amounts (respectively $144 \mathrm{~mm}$ in October in Florence and 152 in November in Oviedo). Average relative humidity was around $70-74 \%$ during the field exposure at all sites, with the highest values in Bucharest. The lowest air thermal value close to the stone samples was measured in Bucharest $\left(-14^{\circ} \mathrm{C}\right.$ in January), where it also snowed heavily at the beginning of February. Nevertheless, Bucharest was the site characterized by the lowest average values of thermo-hygrometric daily variations, respectively of $14^{\circ} \mathrm{C}$ for temperature and $55 \%$ for relative humidity. In the other sites, the average daily thermal variations were of $22-24^{\circ} \mathrm{C}$, whilst the average daily hygrometric variations were between $60 \%$ (Cologne) and $75 \%$ (Florence). The risks for the most important physical damage processes for the material investigated (i.e. condensation, freeze-thaw cycles, salts crystallization etc.) were evaluated, as well as other potentially damage phenomena related to the climatic and microclimatic conditions (i.e. surface heating, thermo-hygrometric cycles, etc.). The results of the microclimatic monitoring are reported in details in [26].

It is well known that pollutants in synergy with environmental factors trigger many damage processes affecting surfaces. According to the methodological approach adopted in the NANOMATCH Project, samples have been placed outdoor, in an unsheltered area and so exposed to the rain-wash out. However, all samples were

Table 1 Lithotypes and sites of exposure selected for the field test within NANOMATCH Project

\begin{tabular}{ll}
\hline Lithotype & Site of exposure \\
\hline Carrara Marble & Santa Croce Basilica Florence, Cologne Cathedral, Oviedo Cathedral, Stavropoleos Monastery Bucharest \\
Savonnières limestone & Cologne Cathedral \\
Laspra dolostone & Oviedo Cathedral \\
Albeşti limestone & Stavropoleos Monastery Bucharest \\
\hline
\end{tabular}


Table 2 Artificial deterioration and consolidating treatments carried out on the four lithotypes

\begin{tabular}{|c|c|c|c|}
\hline Site & $\begin{array}{l}\text { Model sample } \\
(10 \times 10 \times 5) \mathrm{cm}^{3}\end{array}$ & Artificial deterioration & Treatments \\
\hline Florence & Carrara marble & Thermal shock & NANOMATCH1 solution in 1:1 ethanol:ligroin at $20 \mathrm{~g} / \mathrm{L}$ of $\mathrm{Ca}$ \\
\hline \multirow[t]{2}{*}{ Cologne } & Carrara marble & Thermal shock & \\
\hline & Savonnières limestone & Contaminated with a $5 \% \mathrm{w} / \mathrm{w} \mathrm{Na}_{2} \mathrm{SO}_{4}$ solution & \\
\hline \multirow[t]{2}{*}{ Oviedo } & Carrara marble & Thermal shock & COMMERCIAL: CaLoSiL ${ }^{\oplus}-20 \mathrm{~g} / \mathrm{L}$ of Ca in ethanol \\
\hline & Laspra dolostone & - & \\
\hline \multirow[t]{2}{*}{ Bucharest } & Carrara marble & Thermal shock & \\
\hline & Albesti limestone & - & \\
\hline
\end{tabular}

placed in urban environments therefore affected by problems related to the vehicular traffic, domestic heating and industry. Moreover, Cologne, Oviedo and Bucharest have also to face pollution caused by power plants (some of them also fuelled by coal) located within the cities or in their periphery. Oviedo is also placed in a coal mining area, implying a high concentration of $\mathrm{SO}_{2}, \mathrm{NO}_{\mathrm{X}}, \mathrm{CO}_{2}$ and traces of heavy metals in the atmosphere. However in Florence, Oviedo and Bucharest samples were exposed in pedestrian areas and therefore not directly exposed to vehicular traffic impact. On the contrary, Cologne cathedral is aside the railway station and in traffic congested area. The yearly reports about the air quality status for the year 2013 of the four cities confirm the main pollution problems are the still high concentration of nitrogen oxides and particulate matter, both connected with vehicular traffic emissions. Examining the yearly report about the air quality status of Tuscany for the year 2013 [27], some events of pollutants concentration exceeding suggested thresholds were observed in the congested monitoring station of Gramsci Avenue, located near Santa Croce

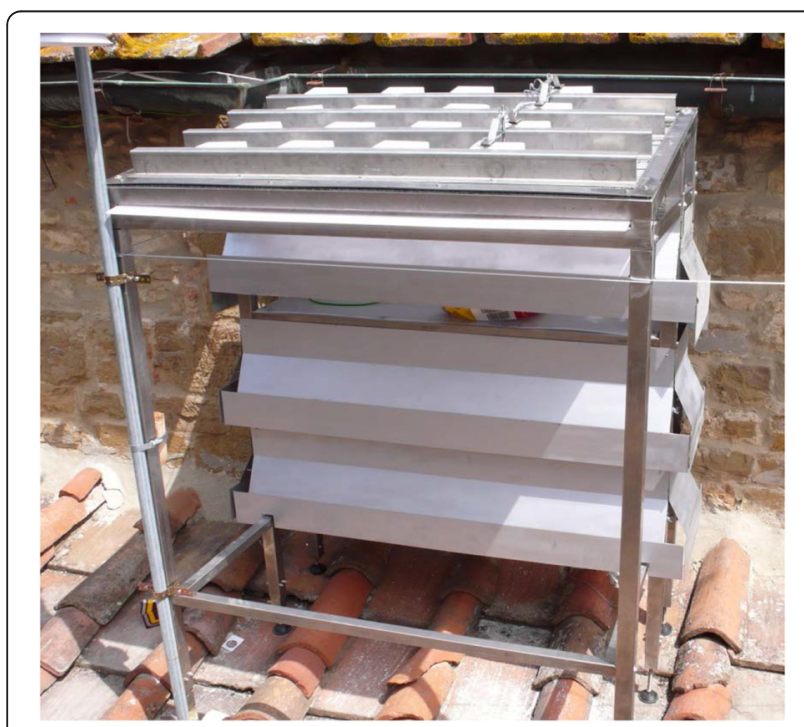

Figure 3 Galvanized rack used for the field exposure test (Santa Croce Basilica, Florence).
Basilica. For example, the daily mean limit value of PM10 regulated by the European Directive 2008/50/EC and the Italian D.Lgs $155 / 2010$ and D.Lgs 250/2012 was not respected as well as the concentration of ozone $\left(\mathrm{O}_{3}\right)$. Moreover, the concentration of $\mathrm{NO}_{2}$ exceeded the annual limit value of $40 \mathrm{\mu gm}^{-3}$. During the 2013 there was also a reduction of the yearly mean concentration of carbon monoxide $(\mathrm{CO})$ and sulfur dioxide $\left(\mathrm{SO}_{2}\right)$. Concerning Cologne, the annual report on air quality of the North RhineWestphalia relative to 2013 [28] highlighted that the amount of particulate matter slightly increased while the hourly limit value of nitrogen dioxide was respected in all the monitoring stations, although some excesses of the annual limit value occurred in congested areas such as the one located near the Cologne Cathedral. An improvement in the concentration of sulfur dioxide and ozone was observed, the latter facilitated by few long sunshine periods and by the decrease in emissions of precursors such as $\mathrm{NO}_{\mathrm{X}}$ and volatile hydrocarbons. During the eleven months of stone samples exposition in Oviedo no excesses in sulfur dioxide concentration were recorded by the monitoring station nearest to the Cathedral, both of the

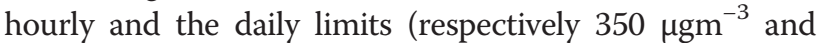
$125 \mathrm{\mu gm}^{-3}$ ) [29]. Moreover, there was an improvement in the emission of ozone in respect to the previous years while the concentration of nitrogen dioxide and particulate overtook the limits, remaining, however, below the number of possible excesses. The Rumanian annual report on air quality relative to 2013 [30] highlighted that the concentration of nitrogen oxides and of the particulate matter were still high in Bucharest while the sulfur dioxide emissions did not manifest any excess of the hourly and daily limit values.

\section{Analytical techniques}

Analyses on model samples have been performed before and after the consolidation treatments with both the NANOMATCH1 and commercial products. Then, samples have been exposed at the sites. Performance in terms of efficacy, compatibility and durability of the newly developed product have been evaluated by comparing results obtained before exposition, and after one 
year of exposure of each treated/untreated stone by means of the following analyses:

- Optical Microscopy (OM) both in transmitted and reflected light on thin and polished cross sections of each lithotype using an Olympus BX51 microscope;

- Scanning Electron Microscopy - Energy Dispersive X-ray spectroscopy (SEM-EDX) using a ZEISS 1530 instrument, equipped with two different Secondary Electrons (SE) detectors, the InLens (IL) and the Everhart-Thornley detectors (ETD);

- Color measurements (spectrophotometry) carried out according to the CIE L"a"b" chromaticity diagram and to the UNI 8941 Standard Colored surfaces, using a KONICA MINOLTA CM700d Spectrophotometer, performing measurements with a spot size of $8 \mathrm{~mm}$ diameter in the $400-700 \mathrm{~nm}$ spectral range.

- Scotch Tape Test (STT)

- Capillarity water absorption test.

Objectives and analyses performed on the four lithotypes are summarized in Table 3.

Cohesion, surface properties, penetration depth, interactions with stone, porosity and water absorption have been therefore evaluated and compared.

\section{Results and discussion}

Analyses on collected samples have been carried out with the aim to verify the cohesive properties conferred to the surface by the treatments, the possible textural and structural modifications induced by the application of the nanomaterials to the stone surface, the penetration depth of the consolidating product, as well as possible interactions with the stone.

In this section the most important contributes obtained from each analytical technique, with exception of capillarity water absorption test, are shown in order to highlight the potentialities of the adopted methodological approach.

Intergranular decohesion induced by thermal shock is clearly visible in OM and SEM images of Carrara marble artificially damaged (Figure 4a and b, respectively). On all analysed samples, the treatment with NANOMATCH1 product has been identified as a surface homogeneous microcrystalline layer, whose thickness and penetration into the stone matrix depend on the lithotype's porosity and petrographic characteristics (Figure 5a, c, e). The treatment performed with $\mathrm{CaLoSiL}^{\bullet}$ (Figure $5 \mathrm{~b}, \mathrm{~d}, \mathrm{f}$ ) also leads to a surface microcrystallization layer characterized by higher thickness values. In addition, the surface layers produced, although they are both constituted by calcium carbonate microcrystals, appear different in terms of compactness and distribution on samples' surfaces. The $\mathrm{CaLoSiL}^{\circ}$ treatment induces the formation of a more compact layer adhering to the surface, while NANOMATCH1 treatment appears less compact, following the surface's shape of the stone, as highlighted by the red arrows in Figure 5.

Analyses performed after exposure have highlighted traces of NANOMATCH1 product within the stone matrix, filling intergranular spaces as calcium carbonate recrystallization (Figure 6a, b).

On the contrary, $\mathrm{CaLoSiL}^{\circ}$ treatment is still clearly visible on Carrara Marble surface after exposure and it appears as a discontinuous brownish surface layer in plane polarized light, and as a bright greenish microcrystalline layer in cross polarized light (Figure 6c, d).

More information about the capability of the product to penetrate into fractures and cracks have been obtained by SEM investigation executed after the exposure. In particular, after 11 month of exposure in Florence and Cologne, morphological observations performed on cross sections of treated sample surfaces demonstrated different decay patterns according to the consolidating treatment (NANOMATCH1 or $\mathrm{CaLoSiL}^{\circ}$ ) and exposure. It can be pointed out that samples from Florence show

Table 3 Analyses performed on the four lithotypes samples and objectives

\begin{tabular}{|c|c|c|c|c|}
\hline Objective & Analysis & When & Lithotype & Site \\
\hline \multirow[t]{2}{*}{ Colour change } & \multirow[t]{2}{*}{ colorimetry } & Before/after treatment & \multirow[t]{2}{*}{ all } & \multirow[t]{2}{*}{ all } \\
\hline & & After exposure & & \\
\hline \multirow{2}{*}{$\begin{array}{l}\text { Cohesion, surface properties, } \\
\text { penetration depth, interaction }\end{array}$} & \multirow[t]{2}{*}{ SEM-EDX } & Before/after treatment & \multirow[t]{2}{*}{ Carrara marble, Savonniéres limestone } & \multirow[t]{2}{*}{ Florence, Cologn } \\
\hline & & After exposure & & \\
\hline \multirow{2}{*}{$\begin{array}{l}\text { Cohesion, penetration depth, } \\
\text { interaction }\end{array}$} & \multirow[t]{2}{*}{$\mathrm{OM}$} & Before/after treatment & \multirow[t]{2}{*}{ Carrara marble, Savonniéres limestone } & \multirow[t]{2}{*}{ Florence, Cologne } \\
\hline & & After exposure & & \\
\hline \multirow[t]{2}{*}{ Cohesion } & \multirow[t]{2}{*}{ ScotchTapeTest } & Before/after treatment & \multirow[t]{2}{*}{ all } & \multirow[t]{2}{*}{ all } \\
\hline & & After exposure & & \\
\hline Water absorption & $\begin{array}{l}\text { capillarity water } \\
\text { absorption }\end{array}$ & $\begin{array}{l}\text { Before treatment/after } \\
\text { exposure }\end{array}$ & $\begin{array}{l}\text { Carrara marble, Savonniéres limestone } \\
\text { (on selected samples purposely prepared) }\end{array}$ & Florence, Cologne \\
\hline
\end{tabular}




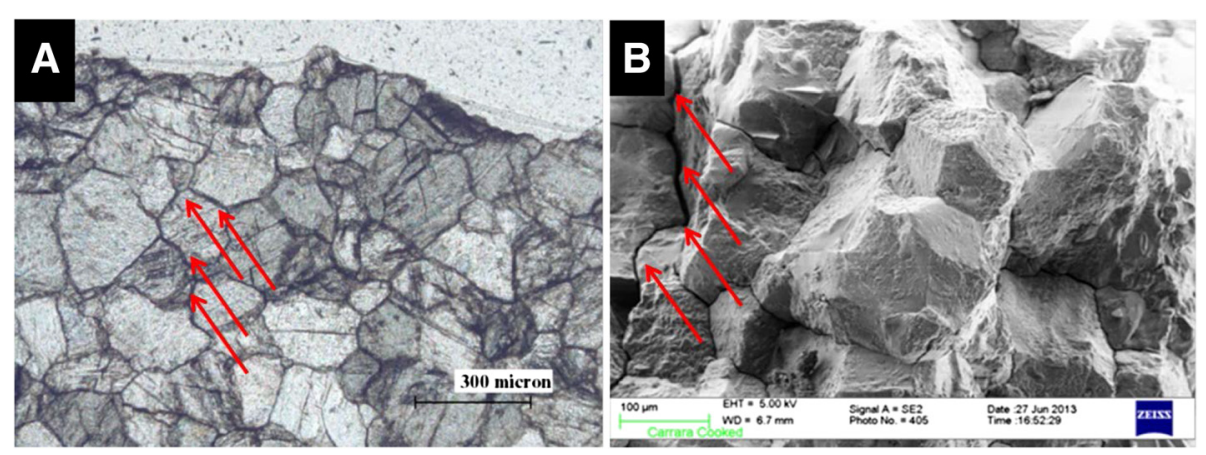

Figure 4 Optical micrograph (plane-polarized light) (a) and scanning electron micrograph (b) of Carrara Marble artificially damaged by thermal shock.
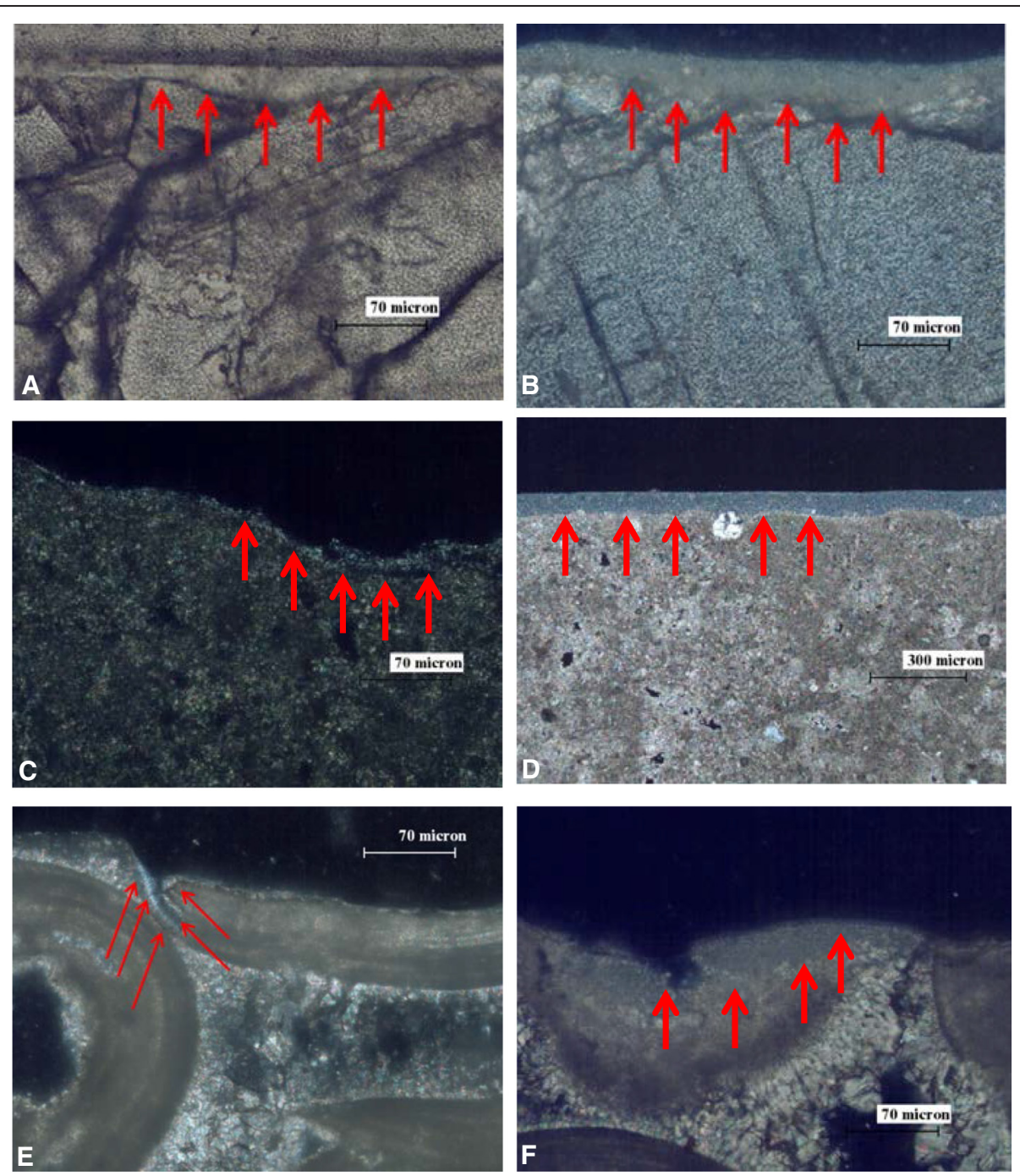

Figure 5 Optical micrographs of: Carrara Marble treated with NANOMATCH1 product (plane-polarized light) (a) and CaLoSiL ${ }^{\circledR}$ (crossedpolarized light) (b); Laspra dolostone treated with NANOMATCH1 product (crossed-polarized light) (c) and CaLoSiL ${ }^{\circledR}$ (crossed-polarized light) (d); Savonnières limestone treated with NANOMATCH1 product (crossed-polarized light) (e) and CaLoSiL ${ }^{\circledR}$ (crossed-polarized light) (f). Red arrows indicate the surface microcrystalline layer formed after the consolidating treatment executed with the two products. 

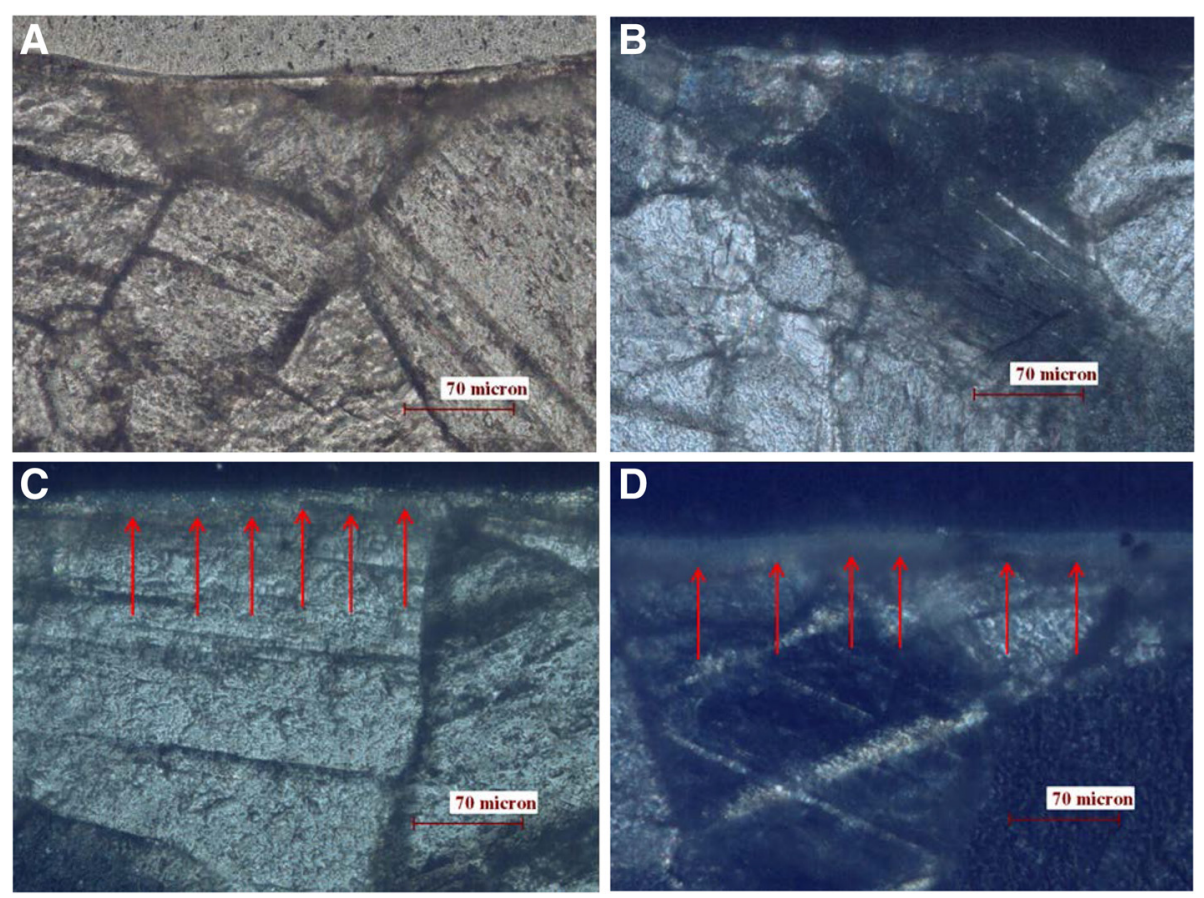

Figure 6 Optical micrographs of: Carrara Marble treated with NANOMATCH1 product after the exposure in plane-polarized light (a) and in crossed-polarized light (b); Carrara Marble treated with CaLoSiL ${ }^{\circledR}$ after the exposure in crossed-polarized light (c, d). Red arrows indicate the surface microcrystalline layer still present on the marble surface.

more severe effects of pitting on the surface, having the treatment layer been thinned and largely removed leaving uncovered and visible crystals of calcite (Figure 7a). This effect can be linked to the acid rain impact that partially dissolved the calcium carbonate formed by the treatment, being stone samples exposed outdoors in unsheltered positions. Taking into account the values of precipitation recorded during the exposure period it should be underlined that Florence, along with Oviedo, has been characterized by the highest cumulative amounts of rainfall during the monitoring campaigns $(820 \mathrm{~mm})$, followed by Cologne $(460 \mathrm{~mm})$. It is known that the main cause of rain acidification is essentially attributable to an increase of carbon dioxide concentration in the air and to other gaseous compounds such as $\mathrm{NO}_{\mathrm{x}}$ and $\mathrm{SO}_{2}$, whose concentration in urban environment is mostly linked to anthropogenic activity. Comparing acidifying agents concentrations registered by the local agencies from $22 / 07 / 2013$ to $31 / 12 / 2013$ it can be noticed that nitrogen oxides concentration registered close to Santa Croce Basilica [27] are higher than those recorded in Cologne [28] (Figure 8). Moreover, a similar distribution has been noticed observing samples treated with NANOMATCH1 product, independently from the site exposure. Indeed, the product is randomly distributed along the inner pores (Figure $7 \mathrm{~b}$ ) forming a superficial coating adhering to the calcite surface on wider pores (pore diameter $>$ 20-30 um). Morphological observations performed on marble treated with $\mathrm{CaLoSiL}^{\circ}$ and exposed in Florence and Cologne showed the uneven presence of the product mainly distributed along the surface (Figure 7d); the pitting effect has been also observed (Figure 7c).

In general, surface treatments adopted in conservation procedure should not strongly modify the aesthetic aspect of the work of art. Spectrophotometric measurements have been performed according to the CIE L*a*b* chromaticity diagram in order to verify if possible differences in colour of surfaces induced by NANOMATCH1 treatment would be noticed and if they might be considered negligible or not. Taking into account the indication given by García and Malaga [31] with regard to the threshold value of $\Delta \mathrm{E}^{*}$ accepted as reference in the evaluation of a conservation treatment, the $\Delta \mathrm{E}^{*}$ values, calculated using colour coordinates referred to the surface of the samples before and after treatment, cannot be seen by a human eye when they are $<5$ units.

Each colour parameter has been acquired for each lithotype before and after the treatment and therefore the total colour difference has been calculated using the formula (1):

$$
\Delta E^{*}=\sqrt{\left(L_{2}^{*}-L_{1}^{*}\right)^{2}+\left(a_{2}^{*}-a_{1}^{*}\right)^{2}+\left(b_{2}^{*}-b_{1}^{*}\right)^{2}}
$$

As shown in Figure 9, the average values of the total colour differences calculated using colour parameters 

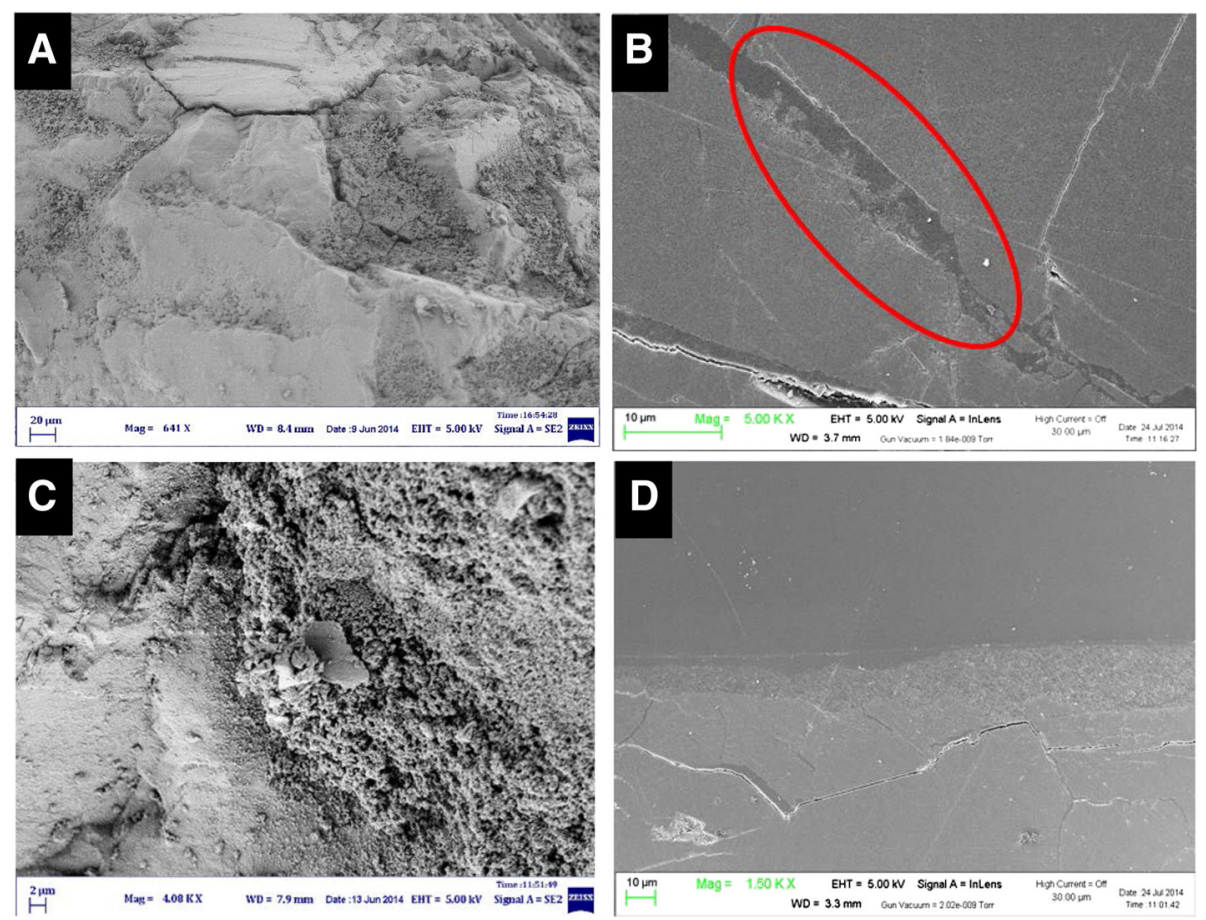

Figure 7 SEM micrographs of Carrara marble treated with: NANOMATCH1 product after exposure, bulk sample (a) and polished crossed section (b); CaLoSiL ${ }^{\circledR}$ product after exposure bulk sample (c) and polished crossed section (d). Red circle indicates the coating formed by the NANOMATCH1 treatment adhering to the calcite surface within pores.

acquired before and after NANOMATCH1 treatment lies under the threshold value $\left(\Delta \mathrm{E}^{*}=5\right)$ for all lithotypes; on the contrary, $\mathrm{CaLoSiL}^{\circ}$ treatment induces total colour differences higher respect to the threshold value, except for Carrara Marble samples. In addition, measurements highlighted that $\mathrm{L}^{*}$ and $\mathrm{b}^{*}$ are the colour parameters principally changing in consequence of the consolidating treatments, leading to a surface whitening and a

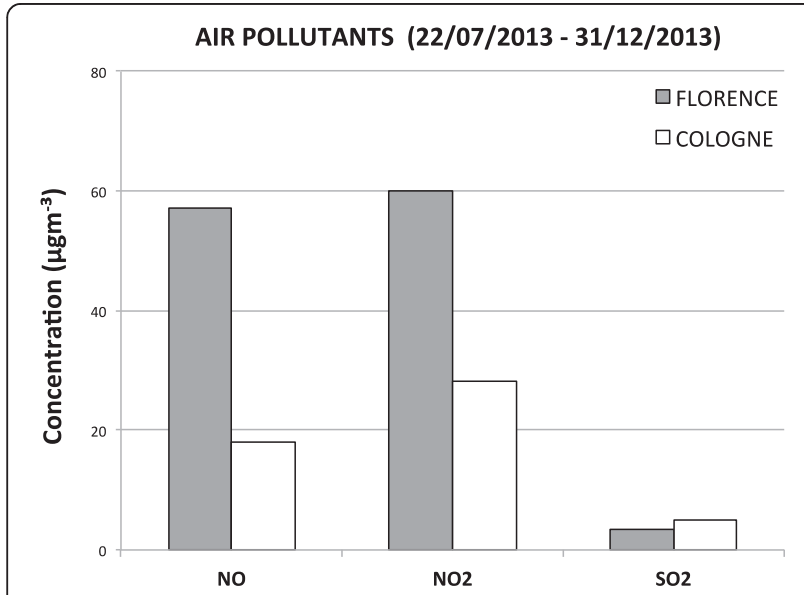

Figure 8 Hourly mean concentration of $\mathrm{NO}, \mathrm{NO}_{2}$ and $\mathrm{SO}_{2}$ registered during the period 22/07/2013-31/12/2013 by the local agencies for the monitoring of the environment and air quality $[27,28]$. yellowing effect respectively. It has been noticed that for a white coloured stone as Carrara Marble, the general increase in $L^{*}$ values is attributable in first instance to the heating treatment. The treatments do not contribute to further increase of this effect. A slight yellowing

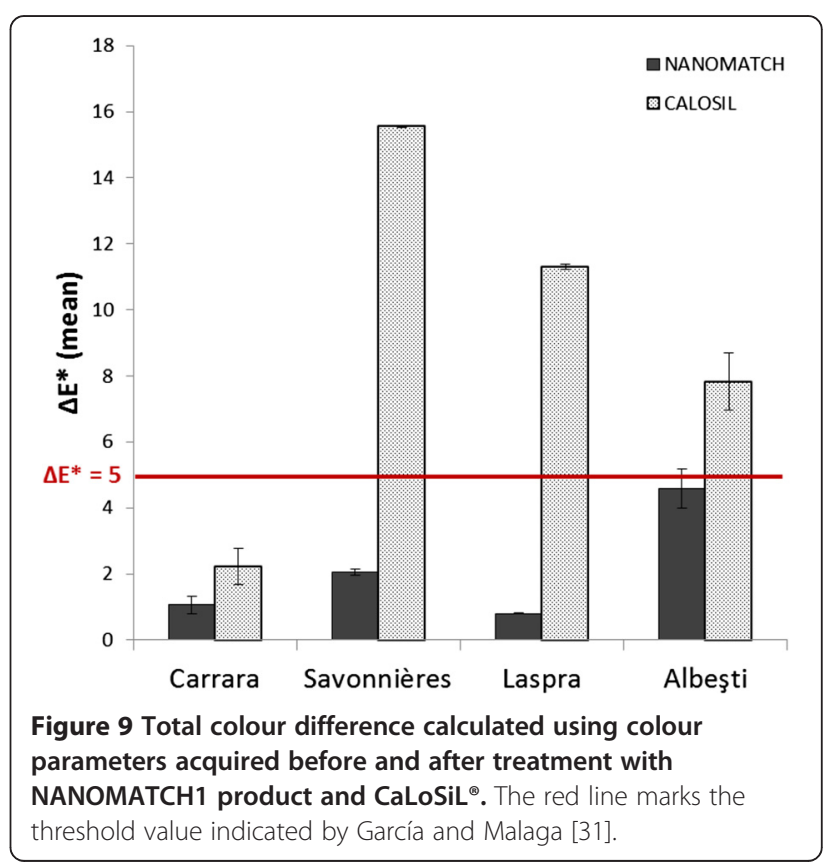




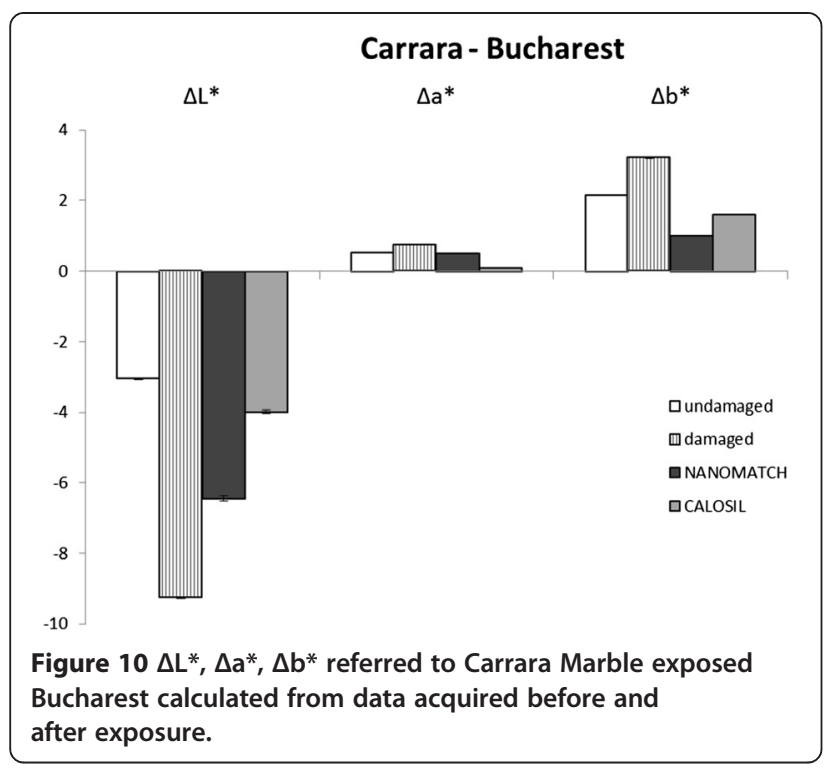

effect has been observed in samples treated with NANOMATCH1 product.

Colour measurements carried out after the exposure have allowed to estimate the colour variation due to the outdoor exposure. Among obtained results, it was interesting to verify which set of samples had undergone major colour changes and, in particular, which colour parameters were mostly involved. In Figure $10 \Delta \mathrm{L}^{*}, \Delta \mathrm{a}^{*}$, $\Delta \mathrm{b}^{*}$ values referred to Carrara Marble exposed in Bucharest, calculated from data acquired before and after exposure are presented. It can be pointed out that the highest variations for each colour parameter are referred to artificially damaged samples where the $\Delta \mathrm{L}^{*}$ reaches the highest negative value $\left(\left|\Delta \mathrm{L}^{*}\right|=9.25\right)$, meaning a more pronounced darkening of the exposed surface with respect to undamaged and treated samples as well.

Surface cohesion characteristics of the stones before and after the consolidating treatment have been assessed by carrying out the peeling test recommended by many authors and standardized by Drdácký et al. [32]. It consists in applying and removing pressure sensitive tape over the surface of interest to evaluate the amount of incoherent material peeled from the surface by gravimetrical analysis (Figure 11). In Figure 12 results among those obtained by performing STT on Carrara marble and Albeşti limestone model samples are presented. In general, STT carried out on all stone samples show that the amount of material peeled from the surface after the NANOMATCH1 treatment is highly reduced as compared to the amount removed before the treatment; moreover, while the test performed on untreated samples highlights a reduction of the quantity of incoherent material removed from the surface in function of the number of peeling executed (the stone is much more detached and mechanically deteriorated on the surface respect to the inner part), samples treated with NANOMATCH1 product show that the amount of removed material is independent from the number of peeling carried out, suggesting a surface hardening effect. On the contrary, $\mathrm{CaLoSiL}^{\circ}$ treatment seems to be ineffective in reducing the detachment of the surface, as the quantity of incoherent material removed before and after treatment are comparable.

Both untreated and treated samples after the exposure show a decrease of the material removed by the peeling action, probably due to the rain compacting action and to calcite dissolution and recrystallization phenomena. As an example, STT results referred to Carrara Marble exposed in Bucharest are reported in Figure 13. Concerning NANOMATCH1 treatment's behaviour, it could be noticed that a positive mild effect of exposure occurred, with general slight increase of cohesion in deeper layers. $\mathrm{CaLoSiL}^{\circ}$ treatment demonstrate best results after exposure respect to before exposure, highlighting the slow kinetics of carbonation reaction being $\mathrm{CaLoSiL}^{\circ}$ constituted by nanoparticles suspended in different alcohols and having sizes ranging between 50 and $150 \mathrm{~nm}$ depending on the production process.

\section{Key outputs}

In this paper the methodological approach adopted by field exposure tests in the EC NANOMATCH project
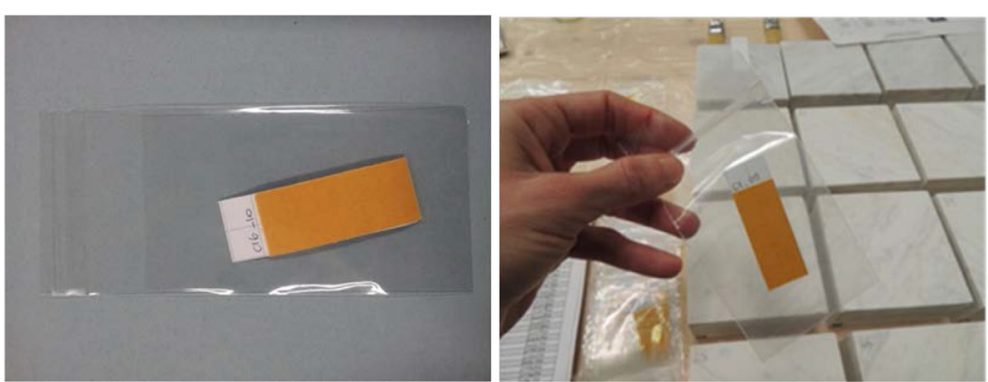

Figure 11 Scotch tape test on Carrara Marble samples. 

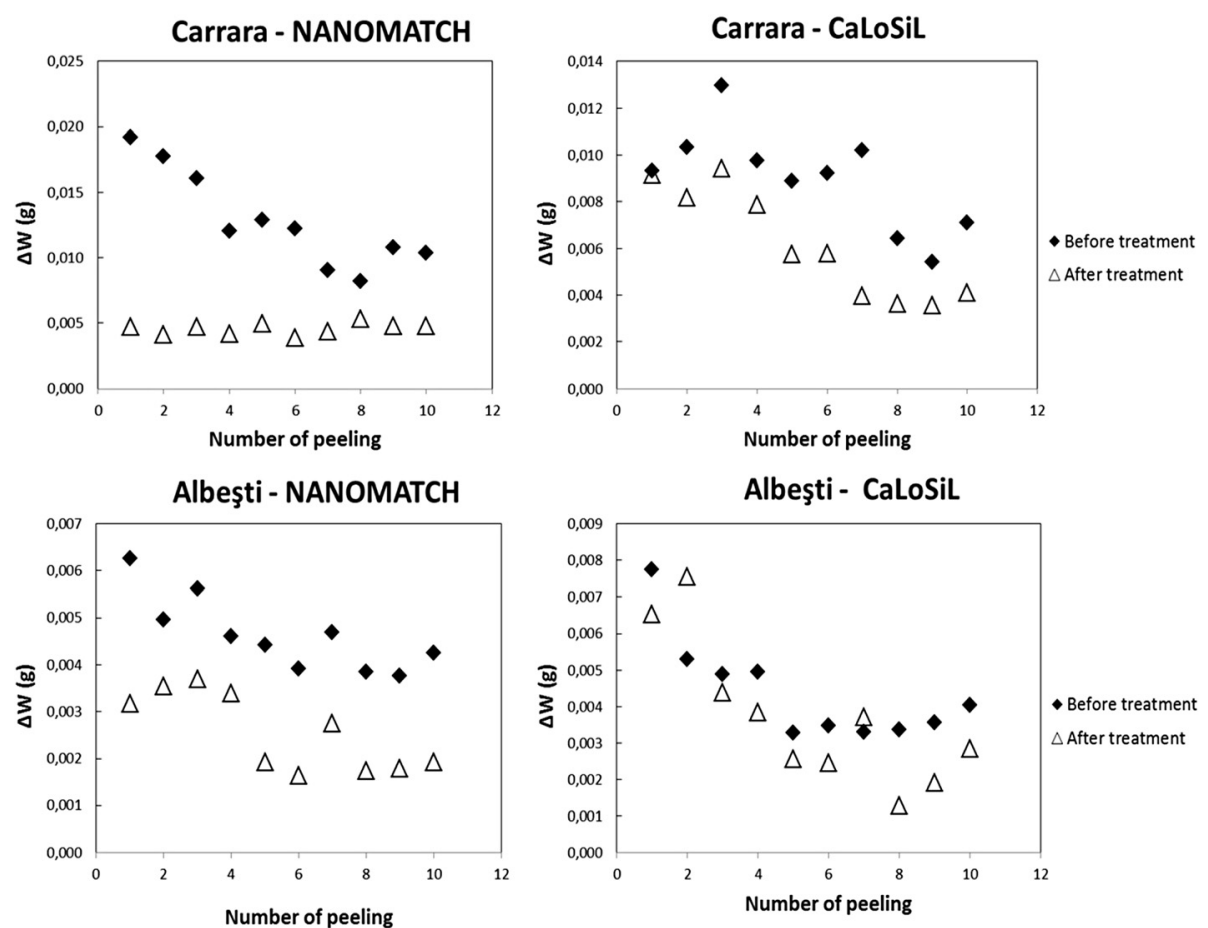

Figure 12 Scotch Tape Test data referred to samples of Carrara Marble (up) and to Albeşti limestone (bottom) treated with the two consolidating agents.

for the evaluation of climate impact on the performances of newly developed products was described. The presented data should be read as part of the preliminary results of the analyses carried out before and after the application of the product on stone samples.

In terms of aesthetic compatibility NANOMATCH1 product can be considered suitable to be used as consolidant for the selected lithotypes as it does not affect the appearance of the stone when appropriately applied. Results showed that it leads to the formation of microcrystalline aggregates on porous limestones' surfaces, somewhere penetrating the stone matrix; on stones characterized by low porosity or microporosity (as Carrara Marble) it forms a discontinuous microcrystalline surface layer. After exposure, morphological observations performed on stone surfaces and sections of samples treated with NANOMATCH1 and $\mathrm{CaLoSiL}^{\circ}$ products, demonstrated that the calcium carbonate coating deriving NANOMATCH1 product is barely observable over the surface and is randomly distributed on wider pores and cracks below the stone surfaces, while the consolidant obtained from carbonation of $\mathrm{CaLoSiL}^{\circ}$ is exclusively located on the outmost surface and it is affected by fissures as the substrate itself due to outdoor weathering.

A good surface cohesive effect is achievable in a short time after its application on stones, due to the fast reactions of alkoxides with atmospheric $\mathrm{H}_{2} \mathrm{O}$ and $\mathrm{CO}_{2}$. Moreover, greater cohesion of the surface has been detected
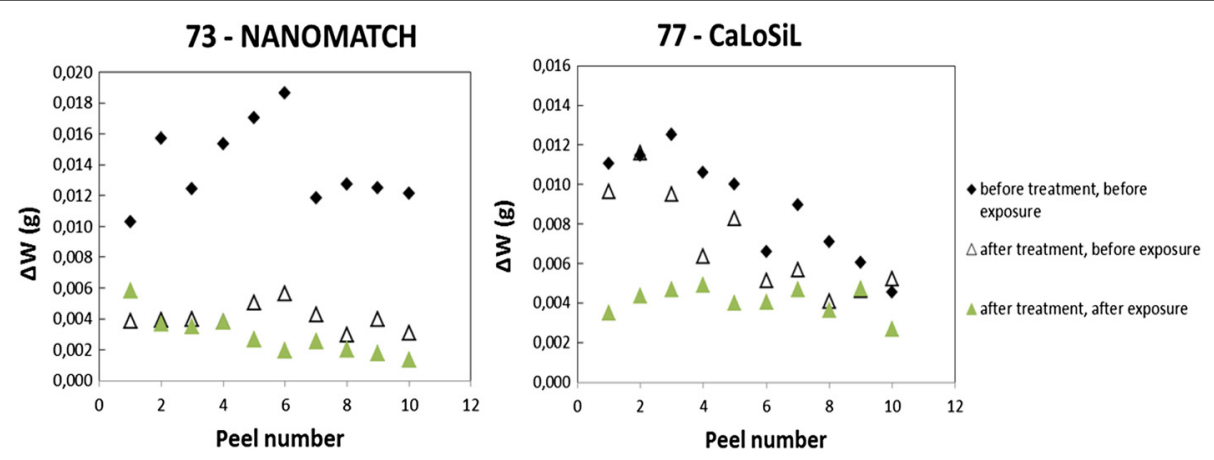

Figure 13 Scotch Tape Test data referred to samples of Carrara Marble treated with the two consolidating agents and exposed in Bucharest. 
after the exposure period, even though the NANOMATCH product is almost absent on the stone surface, as confirmed by optical and electron scanning morphological observations. Comparing and combining OM and SEM results with those obtained by the peeling test (STT) it has been possible to argue for the calcium carbonate deriving from the calcium alkoxide a partial dissolution, penetration and recrystallization of the product within the porous matrix as a consequence of the exposure.

The comparison and the crosschecking of all the results obtained by the analyses of samples before/after treatment and after one year of exposure will allow to evaluate the durability of the nanostructured material developed within the NANOMATCH project and the climatic impact on the innovative treatment and the treated surfaces related to different geographical areas. The preliminary analyses carried out on Carrara Marble, the only lithotype exposed in all the sites, indicate that the differences in the environmental factors present at each site do not translate in significant differences between the marble samples exposed at the different sites.

\section{Competing interests}

The authors declare that they have no competing interests.

\section{Authors' contributions}

All the authors contributed in planning the research activities. IN and PT wrote the paper. AlB and FB critically reviewed the paper. MF and PT synthesized the metalalkoxides and carried out the coating investigation. IDO and PT carried out the application trials. IN and AIB set up the field exposure test. IN and CC performed the Optical Microscopy observation. IN and OF carried out the Scanning Electron Microscopy investigation. IN carried out color measurements and data elaboration. IN, VJFP, MDRS and IDO carried out the Scotch Tape Test and data elaboration. AV and FB performed the climate and microclimate monitoring as well as data processing. AlB coordinated the scientific analyses. AlB, AdB and MF conceived this study. AdB coordinated the project which has funded this research. All authors read and approved the final manuscript.

\section{Acknowledgements}

The NANOMATCH Project (Nano-systems for the conservation of immoveable and moveable polymaterial Cultural Heritage in a changing environment) has received funding from the European Union's Seventh Programme for research, technological development and demonstration under grant agreement No [283182]. Authors express their gratitude to Elsa Bourguignon and Vincent Detalle (CPP- LRMH, France), Barbara Lubelli and Rob Van Hees (TNO, Netherlands), Ulrike Brinkmann and Michael Hauck (Dombauverwaltung Köln, Germany), Martin Labouré (Eschlimann Atelier, France), Marco Pancani (Opera di Santa Croce, Firenze, Italy) and Luis Valdeón (Gea asesoría geológica, Spain) for the fruitful discussion and support during the experimental work.

\footnotetext{
Author details

'Istituto di Scienze dell'Atmosfera e del Clima, Consiglio Nazionale delle Ricerche (ISAC-CNR), Bologna, Italy. ${ }^{2}$ Istituto di Scienze dell'Atmosfera e del Clima, Consiglio Nazionale delle Ricerche (ISAC-CNR), Padova, Italy. ${ }^{3}$ Istituto per l'Energetica e le Interfasi, Consiglio Nazionale delle Ricerche (ISAC-IENI), Padova, Italy. ${ }^{4}$ Dipartimento di Scienze e Ingegneria della Materia, dell'Ambiente ed Urbanistica - Università Politecnica delle Marche, Ancona, Italy. ${ }^{5}$ Instituto Tecnológico de la Construcción (AIDICO), Novelda-Alicante, Spain. ${ }^{6}$ DUCT SRL, Bucuresti, Romania.
}

Received: 30 September 2014 Accepted: 10 February 2015

Published online: 02 March 2015

\section{References}

1. Sabbioni C, Brimblecombe P, Bonazza A, Grossi CM, Harris I, Messina P. Mapping climate change and cultural heritage. In: Proceedings of 7 th EC Prague Conference on Safeguarded Cultural Heritage - Understanding \& Viability for the Enlarged Europe. Prague, Czech Republic: ITAM CAS; 2007.

2. Cassar M. Climate Change and the Historic Environment. London: Published by the Centre for Sustainable Heritage, University College London; 2005.

3. Sabbioni C, Brimblecombe P, Cassar M, editors. The Atlas of Climate Change Impact on European Cultural Heritage. Scientific Analysis and Management Strategies. London, UK: Anthem Press; 2012.

4. Grossi CM, Brimblecombe P, Menéndez B, Benavente $D$, Harris I, Déqué $M$. Climatology of salt transitions and implications for stone weathering. Sci Total Environ. 2011:409:2577-85.

5. Bonazza A, Messina P, Sabbioni C, Grossi CM, Brimblecombe P. Mapping the impact of climate change on surface recession of carbonate buildings in Europe. Sci Total Environ. 2009;407:2039-50.

6. Grossi CM, Brimblecombe P, Harris I. Predicting long term freeze-thaw risks on Europe built heritage and archaeological sites in a changing climate. Sci Total Environ. 2007;377:273-81.

7. Bonazza A, Sabbioni C, Messina P, Guaraldi C, De Nuntiis P. Climate change impact: mapping thermal stress on Carrara marble in Europe. Sci Total Environ. 2009:407:4506-12.

8. Melo MJ, Bracci S, Camaiti M, Chiantore O, Piacenti F. Photodegradation of acrylic resins used in the conservation of stone. Polym Degrad Stab. 1999;66:23-30

9. Favaro M, Mendichi R, Ossola F, Russo U, Simon S, Tomasin P, et al. Evaluation of polymers for conservation treatments of outdoor exposed stone monuments. Part I: Photo-oxidative weathering. Polym Degrad Stab. 2006;91:3083-96.

10. Favaro M, Mendichi R, Ossola F, Simon S, Tomasin P, Vigato PA. Evaluation of polymers for conservation treatments of outdoor exposed stone monuments. Part II: photo-oxidative and salt-induced weathering of acrylic-silicone mixtures. Polym Degrad Stab. 2007;92:335-51.

11. Rodriguez-Navarro C, Ruiz-Agudo E, Ortega-Huertas M, Hansen E. Nanostructured and irreversible colloidal behavior of $\mathrm{Ca}(\mathrm{OH})_{2}$ : implications in cultural heritage conservation. Langmuir. 2005;21:10948-57.

12. Dei L, Salvadori B. Nanotechnology in cultural heritage conservation: nanometric slaked lime saves architectonic and artistic surfaces from decay. J Cult Herit. 2006;7:110-5.

13. Natali I, Saladino ML, Andriulo F, Chillura Martino D, Caponetti E, Carretti E, et al. Consolidation and protection by nanolime: Recent advances for the conservationof the graffiti, Carceri dello Steri Palermo and of the 18th century lunettes, SS.Giuda e Simone Cloister, Corniola (Empoli). J Cult Herit. 2014;15:151-8

14. Ossola F, Tomasin P, De Zorzi C, El Habra N, Chiurato M, Favaro M. New calcium alkoxides for consolidation of carbonate rocks. Influence of precursors' characteristics on morphology, crystalline phase and consolidation effects. New J Chem. 2012;36:2618-24.

15. Favaro M, Tomasin P, Ossola F, Vigato PA. A novel approach to consolidation of historical limestone: the calcium alkoxides. App Organomet Chem. 2008;22:698-704.

16. Duchêne S, Detalle V, Favaro M, Ossola F, Tomasin P, De Zorzi C, et al. Nanomaterials for Consolidation of Marble and Wall Paintings. In: Proceedings of the 12th International Congress on the Deterioration and Conservation of Stone. New York, USA: Columbia University; 2012.

17. Bonazza A, Sabbioni C, Lopez-Aparicio S, Tittarelli F, Ozga I. Identification of pollutants and parameters affecting Cultural Heritage conservation and their change in the near and far future, TeACH project. Deliverable 2.1. www.isac. cnr.it/ microcl/staff/bernardi.php.

18. Bonazza A, Sabbioni C, Van Grieken R, Kontozova V, Krupinska B, Gatto Rotondo G. Prioritization of the most important pollutants and parameters for a preventive conservation of the immovable cultural heritage, TeACH project. Deliverable 2.2. www.isac.cnr.it/ microcl/staff/bernardi.php

19. Lopez-Aparicio S, Grøntoft T, Bonazza A. Prioritization of the most important pollutants and parameters for a preventive conservation of the movable cultural heritage, TeACH project. Deliverable 2.3. www.isac.cnr.it/ microcl/ staff/bernardi.php

20. Sabbioni C, Bonazza A, Messina P. Global Climate Change and Archaeological Heritage: Prevision, Impact and Mapping. In: Nicolò M, Ingolf T, editors. ARCHAIA - Case studies on Research Planning, 
Characterisation, Conservation and Management of Archaeologial Sites. Oxford, UK: Archaeopress; 2008.

21. Grøntoft T, Larssen S, Svenningsen G, Hamilton R, Ionescu A, Le Fèvre R, et al. Final assessment model for cultural heritage, CULT-STRAT Project. Deliverable 9. www.corr-institute.se

22. Drake SR, Otway DJ. The synthesis of metal organic compounds of calcium, strontium and barium by ammonia gas-saturated ethereal solvents. J Chem Soc Chem Commun. 1991;7:517-9.

23. Turova NY, Turevskaya EP, Kessler VG, Yanovskaya MI. The Chemistry of Metal Alkoxides. US: Springer; 2002

24. Favaro M, Chiurato M, Tomasin P, Ossola F, El Habra N, Brianese N, Svensson I, Beckers E, Forrat Pérez V, Romero Sánchez M, Orial G, Bourguignon E, Bernardi A. Alkaline earth alkoxides for conservation treatment of stone and wood in built heritage. In Proceedings of 3rd European Workshop on Cultural Heritage Preservation (EWCHP) Bolzano, Italy. 2013.

25. Favaro M, Chiurato M, Tomasin P, Ossola F, El Habra N, Svensson I, Beckers E, Forrat Pérez V, Romero Sánchez M, Bernardi A. Calcium and magnesium alkoxides for conservation treatment of stone and wood in built heritage. In on-line Proceedings of Built Heritage Conference 2013 Monitoring Conservation Management. Milano, Italy. 2013.

26. Pockelé L, De Grandi S, Becherini F, Bernardi A, Vivarelli A. Assessment of the climatic measurement on sites, Nanomatch project. Deliverable 4.2 http://www.nanomatch-project.eu.

27. ARPAT, Agenzia Regionale per la Protezione Ambientale della Toscana www.arpat.toscana.it.

28. Landesamt für Natur, Umwelt und Verbraucherschutz NRW www.lanuv.nrw. de.

29. Oviedo.es Ayuntamiento www.oviedo.es.

30. Ministerul Mediului, Apelor și Pădurilor - Agenția Națională pentru Protecția Mediului www.anpm.ro

31. García O, Malaga K. Definition of the procedure to determine the suitability and durability of an anti-graffiti product for application on cultural heritage porous materials. J Cult Herit. 2012;13:77-82.

32. Drdácký M, Lesák J, Rescic S, Slížková Z, Tiano P, Valach J. Standardization of peeling tests for assessing the cohesion and consolidation characteristics of historic stone surfaces. Mater Struct. 2012;45:505-20.

\section{Publish with ChemistryCentral and every scientist can read your work free of charge \\ "Open access provides opportunities to our colleagues in other parts of the globe, by allowing anyone to view the content free of charge." \\ W. Jeffery Hurst, The Hershey Company. \\ - available free of charge to the entire scientific community \\ - peer reviewed and published immediately upon acceptance \\ - cited in PubMed and archived on PubMed Central \\ - yours - you keep the copyright \\ Submit your manuscript here: \\ http://www.chemistrycentral.com/manuscript/<smiles>c1ccccc1</smiles> \\ Chemistry Central}

